\title{
Laparoscopic management of Hydatid cyst
}

Anang Pangeni, Vikal Chandra Shakya

Department of Surgery, Civil Service Hospital, Minbhawan, Kathmandu

Correspondence : Anang Pangeni, Registrar, Civil Service Hospital, Minbhawan, Kathmandu

Email: anangpangeni@gmail.com

\section{ABSTRACT}

Introduction and Objective: Hydatid cyst of the liver is a fairly common parasitic condition. We present here a series of 9 patients with hydatid cyst of the liver managed by minimally invasive surgery

Materials and Methods: It was a prospective study in patients presenting with hydatid cyst of the liver to Surgery Department who were managed laparoscopically from January 2013 to November 2015.

Result: There were 9 patients ( 5 males and 4 females). The mean operative time was $124+32$ minutes. One patient developed mild allergy in the form of skin rashes on $3^{\text {rd }}$ postoperative day, and another patient developed cholangitis which resolved on conservative management. There was no conversion.

Conclusion: Laparoscopic management of hydatid cysts is possible, and looks promising provided we have advanced energy sources.

Keywords: hydatid cyst; laparoscopy; cystectomy 